\title{
Trazendo os governos de volta: a chefia do executivo e os resultados do ativismo institucional LGBT (2003-2014]
}

\section{Matheus Mazzilli Pereira*}

\section{Resumo}

A recente literatura sobre as relações entre movimentos sociais e o Estado no Brasil tem analisado a influência de ativistas institucionais que atuam na burocracia do Poder Executivo sobre as políticas públicas, caracterizando os limites e as possibilidades de sua ação a partir das particularidades das instituições nas quais estão inseridos. Este trabalho apresenta uma análise comparada da trajetória e dos resultados do ativismo institucional LGBT em quatro órgãos do Poder Executivo no nível federal entre 2003 e 2014. Os resultados da análise indicam, em primeiro lugar, que, apesar de suas distintas trajetórias e configurações em relação ao ativismo LGBT, tais órgãos apresentaram uma queda semelhante nos resultados produzidos por burocratas ativistas LGBT a partir do primeiro Governo Dilma. Em segundo lugar, indicam que, a partir desse período, a chefia do Executivo passou a intervir de forma semelhante em diferentes ministérios e secretarias, criando obstáculos comuns à ação dos ativistas LGBT neles inseridos. Argumenta-se, assim, que os resultados do ativismo institucional são também condicionados pelas intervenções realizadas pela chefia do Executivo em seus ministérios e secretarias, tornando-se necessário "trazer os governos de volta" à análise das relações entre movimentos sociais e o Estado no Brasil.

Palavras-chave: movimentos sociais, governos, políticas públicas, ativismo institucional, movimento LGBT.

* Universidade Vila Velha, Vila Velha, ES, Brasil. 


\section{Bringing governments back in: the chief executive and the outcomes of LGBT institutional activism (2003-2014)}

\section{Abstract}

The recent literature on the relations between social movements and State in Brazil has analyzed the influence of institutional activists that work within the bureaucracy of the Executive branch formulating public policies. It explains the limits and possibilities of their action through the analysis of the particular institutions in which they act. This work presents a comparative analysis of the trajectory and outcomes of the LGBT institutional activism in four government departments of the Executive branch in the federal level between 2003 and 2014. The results show, first, that in spite of presenting different trajectories and configurations regarding the LGBT activism, those offices present a similar decrease in the outcomes of LGBT institutional activism since the first Rousseff administration. Second, the results show that since this administration, the chief Executive started to intervene in those different departments, creating similar obstacles for the LGBT activism operating within them. Considering these data, I argue that the outcomes of the institutional activism are also conditioned by the interventions of the chief Executive its departments. Therefore, it is necessary to "bring the governments back" to the analysis of the relationships between social movements and State in Brazil.

Keywords: social movements, governments, public policy, institutional activism, LGBT movement.

\section{Introdução}

m maio de 2011, a presidenta Dilma Rousseff (Partido dos Trabalhadores - PT) veio a público decretar seu veto à distribuição do material didático produzido no âmbito do projeto Escola sem Homofobia, apelidado pela militância conservadora de "kit gay". Na ocasião, a presidenta declarou que a nenhum órgão de governo seria permitido "fazer propaganda

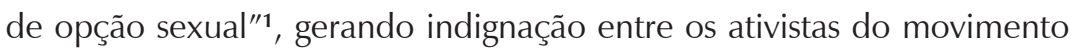
brasileiro de lésbicas, gays, bissexuais, travestis e transexuais (LGBT), em

1Ver Agência Brasil (2011). 
especial entre aqueles que atuavam no Ministério da Educação (MEC) ou em parceria com este órgão na defesa e no desenvolvimento do material.

Apesar de sua repercussão destacada, tal veto não foi um evento isolado. No ano seguinte, de acordo com ativistas LGBT que faziam parte dos quadros do Ministério da Saúde (MS), a presidência impediu a divulgação de uma campanha de prevenção às Doenças Sexualmente Transmissíveis (DST) no carnaval, que tinha como um de seus públicos-alvo jovens gays. Paralelamente, burocratas de outros órgãos do Executivo Federal também enfrentavam dificuldades, tais como a escassez de recursos e perda de espaços burocráticos para sua articulação.

A literatura brasileira recente sobre as relações entre movimentos sociais, Estado e políticas públicas tem destacado os processos de interpenetração entre política institucional e extrainstitucional (Abers; Von Büllow, 2011; Cayres, 2017; Silva, 2015; Tatagiba, 2010). Em especial, tem analisado o fenômeno do ativismo institucional, ou seja, as ações realizadas no interior das instituições políticas em defesa das causas de um movimento social ${ }^{2}$ por indivíduos ligados a suas organizações ou simpáticos a suas demandas (Abers; 2015; 2019; Abers; Serafim; Tatagiba, 2014; Albuquerque, 2015; Cayres, 2017; Ferreira; Lotta, 2016; Rech, 2016; Silva; Oliveira, 2011; Tatagiba; Teixeira, 2016).

Opondo-se a perspectivas que interpretam as relações entre movimentos sociais e política institucional como sinais de "cooptação" do ativismo político, esses estudos têm indicado que o ativismo institucional é capaz de produzir, em certas circunstâncias, resultados em termos de políticas públicas (Dowbor; Carlos; Albuquerque, 2018; Tatagiba; Teixeira, 2016). Essa literatura tem associado as possibilidades de influência de ativistas institucionais sobre as políticas públicas de seu interesse às características, trajetórias e relações de força peculiares a cada órgão de governo específico

${ }^{2} \mathrm{O}$ ativismo institucional não necessariamente é protagonizado por indivíduos com vínculos prévios com organizações de movimentos sociais, também podendo ser realizado por burocratas não vinculados a essas organizações, que agem na defesa das causas de um movimento por compartilharem com ele concepções sobre as políticas públicas (Abers, 2015; 2019; Tatagiba; Teixeira, 2016). 
no qual estão inseridos (Abers; Serafim; Tatagiba, 2014; Carlos; Dowbor; Albuquerque, 2017; Gurza Lavalle et al., 2017; 2019).

Ao delimitar seu foco de análise às dinâmicas internas aos ministérios e secretarias - ou, de forma mais ampla, aos subsistemas de políticas públicas e seus atores (Capella; Brasil, 2015) - essa literatura tem secundarizado os impactos das intervenções da chefia do Executivo em tais órgãos sobre as possibilidades de ação dos ativistas neles inseridos. Frente a essa lacuna, este trabalho busca responder à seguinte questão: de que formas as intervenções da chefia do Executivo em sua burocracia influenciam os resultados do ativismo institucional?

Exploro essa pergunta em um estudo de caso do ativismo institucional LGBT no Poder Executivo em nível federal entre os anos de 2003 e 2014. Analiso de forma comparada a trajetória, os resultados e as intervenções da chefia do Executivo em relação a esse tipo de ativismo no âmbito de quatro ministérios e secretarias do Governo Federal: Ministério da Educação (MEC), Ministério da Saúde (MS), Ministério da Cultura (MinC) e Secretaria de Direitos Humanos (SDH). Os resultados da pesquisa empírica indicam que, apesar das diferentes trajetórias de interação com movimentos sociais e dos distintos pontos de acesso e relações de poder observados em cada um desses órgãos, o ativismo institucional LGBT sofreu intervenções semelhantes da chefia do Executivo nesses ministérios e secretarias, produzindo-se uma trajetória semelhante em seus resultados.

Nesse sentido, em consonância com trabalhos anteriores (Pereira, 2018a), argumento que, apesar de heterogêneo, o Estado brasileiro não deve ser concebido como uma "colcha de retalhos" de instituições completamente autônomas. É preciso resgatar a agência dos governos em suas tentativas de gerenciamento da heterogeneidade estatal na análise das oportunidades políticas (Tarrow, 2009) que se apresentam para movimentos sociais influenciarem políticas públicas. Em trabalhos anteriores destaquei que governos são heterogêneos do ponto de vista de suas coalizões de sustentação no Congresso Nacional e que o gerenciamento dos interesses dos membros dessas coalizões afeta as oportunidades políticas para os movimentos sociais 
(Pereira, 2018a). Aqui, destaco que governos são heterogêneos também no que se refere à sua burocracia e que o gerenciamento realizado pela chefia do Executivo sobre os órgãos a ela subordinados, de forma a conciliar seus próprios interesses, os interesses de sua coalizão e os interesses da burocracia, afeta, igualmente, as oportunidades políticas que se apresentam para movimentos sociais influenciarem políticas públicas.

Para explorar esse argumento, este artigo está dividido da seguinte forma: na próxima seção, analiso a literatura brasileira recente sobre movimentos sociais, ativismo institucional e políticas públicas. A seguir, descrevo os dados e métodos utilizados na pesquisa empírica, cujos resultados são apresentados nas duas seções seguintes. Na primeira delas, descrevo os quatro órgãos de governo analisados no que se refere às distintas trajetórias e características de suas relações com o movimento LGBT. Contrasto tais diferenças às semelhanças observadas nas trajetórias das políticas públicas para pessoas LGBT nesses ministérios e secretarias. A seguir, descrevo as intervenções realizadas nesses órgãos pela chefia do Executivo, em busca de explicações para os resultados observados. Por fim, apresento minhas considerações finais sobre a pesquisa.

\section{Ativismo institucional e seus efeitos em políticas públicas}

Nos últimos anos, a literatura brasileira sobre as relações entre movimentos sociais, instituições políticas e políticas públicas tem criticado premissas dicotômicas presentes em abordagens nacionais e internacionais que concebem movimentos sociais como atores externos às instituições políticas com as quais deveriam manter, necessariamente, relações de confronto para produzir resultados em termos de políticas públicas sem correr o risco de serem "cooptados" (Abers; Von Bullow, 2011; Carlos, 2015a; Cayres, 2017; Silva, 2015; Tatagiba, 2010). Assim, a literatura aponta que movimentos sociais, em diversos momentos, utilizam táticas institucionais em combinação com táticas extrainstitucionais de ação em suas rotinas de interação com o Estado. Táticas institucionais incluem, por 
exemplo, a presença em canais institucionalizados de participação política e a ocupação de cargos na burocracia estatal (Abers; Serafim; Tatagiba, 2014; Albuquerque, 2015; Carlos, 2015b; Cayres, 2017; Ferreira; Lotta, 2016; Rech, 2016; Silva; Oliveira, 2011; Tatagiba; Teixeira, 2016). Em linhas gerais, portanto, essa literatura tem destacado as interpenetrações entre Estado e sociedade civil e entre a "política das ruas" e a "política dos gabinetes", em especial, a partir da análise do "ativismo institucional" (Abers 2015; 2019; Banaszak, 2005; 2009; Cayres, 2017; Pettinicchio, 2012), ou seja, das ações que ocorrem no interior das instituições políticas em defesa das causas de um movimento social.

Um importante argumento apresentado por essa literatura sugere que o uso de táticas institucionais - como, por exemplo, a ocupação de cargos na burocracia estatal - por movimentos sociais não implica necessariamente sua desmobilização e cooptação, já que seu uso tem sido empiricamente observado em combinação com o uso de táticas extrainstitucionais de ação. Nesse sentido, relações de confronto e cooperação entre movimentos sociais, Estados, governos e partidos não são mutuamente excludentes (Abers; Serafim; Tatagiba, 2014; Tatagiba; Teixeira, 2016). Essa literatura sugere, também, que movimentos sociais são, em muitos casos, capazes de influenciar políticas públicas em direção a suas crenças, a partir da combinação entre táticas institucionais e extrainstitucionais de ação (Dowbor; Carlos; Albuquerque, 2018; Penna, 2015; Tatagiba; Abers; Silva, 2018; Tatagiba; Teixeira, 2016).

Assim, uma pergunta se tornou fundamental para essa agenda de pesquisa: em quais condições movimentos sociais podem influenciar políticas públicas, em especial, por meio de táticas institucionais de ação? Para responder a essa e outras questões correlatas, essa literatura, de um modo geral, tem focado sua análise nas dinâmicas de conflito e cooperação relativas aos órgãos nos quais ocorre o ativismo institucional (Abers; Serafim; Tatagiba, 2014; Abers; Silva; Tatagiba, 2018; Carlos; Dowbor; Albuquerque, 2017; Gurza Lavalle et al., 2017; 2019; Tatagiba; Abers; Silva, 2018). Assim, nessa abordagem, 
[o] estado deixa de se configurar em análises apenas como uma oportunidade política e aparece como um conjunto heterogêneo de instituições e burocracias marcado pelo legado institucional e pela agência de seus atores (Carlos; Dowbor; Albuquerque, 2017, p. 370).

Abers, Sefafim e Tatagiba (2014), por exemplo, argumentam que a trajetória histórica de interação entre cada ministério e secretaria de governo com a sociedade seria um fator essencial para compreender as possibilidades de ação encontradas por ativistas institucionais inseridos nessas estruturas. Nesse sentido, destacam a influência dos canais de interação entre Estado e sociedade, do alinhamento de interesses e do estabelecimento de relações de cooperação entre a burocracia e os movimentos sobre o ativismo institucional.

Já inspirados pela abordagem neoinstitucionalista histórica de Theda Skocpol (1985; 1995), outros pesquisadores argumentam que a capacidade de influência de movimentos sociais sobre certa área de políticas públicas depende das características dos "encaixes institucionais"3 por eles encontrados na burocracia estatal (Carlos; Dowbor; Albuquerque, 2018; Gurza Lavalle et al., 2017; 2019). A potência dos encaixes institucionais pode variar em dois sentidos. Em primeiro lugar, os encaixes institucionais podem ter naturezas distintas - podendo ser, por exemplo, órgãos, regras, cargos ocupados ou programas de políticas públicas - que têm implicações para as possibilidades de ação dos ativistas. Em segundo lugar, os encaixes institucionais variam de acordo com sua posição na hierarquia estatal e com sua capacidade de mobilizar a burocracia em favor dos projetos dos ativistas neles situados (Gurza Lavalle et al., 2017; 2019).

Essa literatura apresenta como uma de suas principais contribuições, portanto, "trazer o Estado de volta" (Skocpol, 1985) para as análises da ação coletiva, a partir do pressuposto da interpenetração entre Estado e "Encaixes institucionais são definidos por esses autores como "sedimentações institucionais
de processos de interação socioestatal que ganham vida própria (artefatos: instrumentos,
regras, leis, programas, instâncias, órgãos) e mediante as quais os atores sociais são, em
alguma medida, bem-sucedidos em dirigir de modo contínuo a seletividade das instituições
políticas ao seu favor, ampliando sua capacidade de agir" (Gurza Lavalle et al., 2019, p. 47). 
sociedade e da heterogeneidade estatal. Nesse sentido, muitos de seus autores têm sugerido uma maior aproximação entre teorias dos movimentos sociais e abordagens teóricas no estudo das políticas públicas que enfatizem as interações socioestatais no âmbito dos subsistemas de políticas públicas (Abers; Silva; Tatagiba, 2018; Barcelos; Silva; Pereira, 2016; Tatagiba; Abers; Silva, 2018). No presente trabalho, compartilho das premissas apresentadas por essa literatura. Porém, sugiro um adendo.

Argumento que a heterogeneidade estatal não deve ser interpretada como sinônimo de uma completa autonomia e independência de suas instituições particulares. Sugiro, nesse sentido, ser necessário analisar como governos buscam gerenciar a heterogeneidade dos diversos interesses que compõem a burocracia estatal, em busca da efetivação de seus próprios projetos políticos, assim influenciando o ativismo institucional e seus efeitos sobre as políticas públicas ${ }^{4}$. Em outras palavras, proponho ser é necessário "trazer os governos de volta"5 às análises sobre as relações entre movimentos sociais e políticas públicas, tomando-se o Estado como uma heterogeneidade gerenciada.

Em trabalhos anteriores, destaquei um primeiro sentido dessa heterogeneidade: no caso brasileiro, coalizões de governo tendem a ser ideologicamente heterogêneas, impondo-se à chefia do Executivo a necessidade de conciliar preferências potencialmente contraditórias dos diferentes partidos da coalizão sobre determinadas áreas de políticas

${ }^{4}$ Uma proposta semelhante é apresentada por Abers, Silva e Tatagiba (2018) e Tatagiba, Abers e Silva (2018), ao sugerirem que os efeitos de movimentos sociais sobre políticas públicas são mediados não apenas pela posição dos movimentos sociais em subsistemas de políticas públicas, mas também por sua inserção em dado regime político, incluindo-se na definição de "regimes" as coalizões governantes. Neste trabalho, separo o debate sobre regimes políticos (os padrões de interação entre Estado e sociedade civil mais democráticos ou autoritários) do debate sobre governos (as diferentes coalizões governantes que lideram o Estado em períodos específicos de um regime), focando-me na segunda dessas dimensões. ${ }^{5} \mathrm{~A}$ importância dos governos e da chefia do Executivo não foi ignorada por essa literatura. Estudos destacam, por exemplo, que a ampliação da permeabilidade do Estado para o ativismo institucional de determinados movimentos progressistas é uma particularidade dos governos federais petistas. O papel da chefia do Executivo em grande parte dessas análises, porém, foi reduzido ao aumento e à diminuição da permeabilidade estatal, secundarizando-se a análise da influência dos governos sobre o ativismo institucional uma vez que movimentos sociais tenham encontrado encaixes institucionais. 
públicas. No Brasil, portanto, os próprios governos são heterogêneos em suas preferências e interesses (Pereira, 2018a). Aqui, retomo um segundo sentido dessa heterogeneidade estatal, já destacado pela literatura revisada nesta seção. Quando um governo chega ao poder, encontra uma série de instituições com trajetórias, características e disputas próprias. Para implementar seu projeto político - ou ceder espaços para seus colegas de coalizão - um governo precisa, portanto, gerenciar essa heterogeneidade interferindo sobre os conflitos que ocorrem no interior das instituições a ele subordinadas.

Em relação ao caso em análise, no restante deste artigo buscarei demonstrar como a chefia do Executivo interveio em diversos ministérios e secretarias de governo de formas semelhantes a partir do primeiro Governo Dilma. Sugiro que essas intervenções foram motivadas por conflitos existentes entre os projetos políticos de membros conservadores de sua coalizão e de parte da burocracia estatal em torno de um tema em relação ao qual suas preferências não eram claras: os direitos sexuais ${ }^{6}$. Tais intervenções criaram obstáculos para ativistas institucionais LGBT e, assim, uma queda semelhante nos resultados produzidos por esses ativistas pode ser observada a partir desse período, em órgãos cujas relações com o ativismo LGBT têm trajetórias e configurações distintas.

\section{Dados e métodos}

O objetivo geral deste artigo é compreender como as trajetórias e características internas de três ministérios e uma secretaria de governo (MEC, MinC, MS e SDH) ${ }^{7}$ e as interferências da chefia do Executivo federal em tais órgãos influenciaram os resultados obtidos pelo ativismo institucional

\footnotetext{
${ }^{6}$ Isso ocorre na medida em que o PT, apesar de se ter consolidado como um dos partidos em que as demandas do movimento LGBT foram mais bem recebidas (Cruz, 2017), historicamente manteve uma postura ambígua em relação a essas demandas (De-la-Dehesa, 2007).

7Esses órgãos foram selecionados por terem sido identificados nos estágios iniciais da pesquisa empírica como aqueles que dedicaram o maior volume de recursos para políticas LGBT.
} 
LGBT no período entre os dois primeiros governos Lula (2003-2010) e o primeiro governo Dilma (2011-2014) $)^{8}$. Para atingir esse objetivo geral, foram estabelecidos três objetivos específicos: a) descrever as trajetórias e as características das interações entre esses ministérios e ativistas LGBT; b) mapear as intervenções realizadas em tais órgãos pela chefia do Executivo no período em análise; e c) identificar variações nas políticas de combate à homofobia e garantia dos direitos LGBT em cada um desses órgãos.

Para atingir o primeiro desses objetivos específicos, foram analisadas as dimensões da trajetória das interações entre Estado e sociedade nesses órgãos (Abers; Serafim; Tatagiba, 2014) e das características dos "encaixes institucionais" neles encontrados pelo movimento LGBT (Carlos; Dowbor; Albuquerque, 2018; Gurza Lavalle et al., 2017; 2019). Para operacionalizar a primeira dessas dimensões, em primeiro lugar, descreveu-se a trajetória recente das interações entre o movimento LGBT e esses ministérios e secretaria, no que se refere ao alinhamento de crenças e ao estabelecimento de relações de cooperação entre ativistas LGBT e burocratas. Em segundo lugar, identificou-se a prevalência dos grupos de burocratas que mais fortemente se envolveram em esforços de cooperação com o movimento LGBT no interior desses órgãos ao longo dessa trajetória.

Já a segunda dimensão foi operacionalizada a partir da análise das variações horizontais e verticais de um tipo específico de encaixe institucional: as estruturas burocráticas utilizadas como pontos de acesso dos ativistas às instituições políticas. Devido a esse recorte, no que concerne às variações horizontais, em lugar de focar a variedade dos tipos de encaixe institucional, a análise voltou-se para o domínio e o poder de influência dos ativistas institucionais LGBT sobre esse tipo específico de encaixe em cada caso. No que se refere às variações verticais, como as diversas estruturas burocráticas aqui analisadas estão situadas em posições hierárquicas semelhantes, mapeou-se o apoio dado pelas chefias de cada um desses órgãos às ações desenvolvidas por burocratas ativistas LGBT no âmbito dessas estruturas.

${ }^{8}$ Este artigo apresenta parte dos resultados de uma pesquisa mais ampla realizada no âmbito do doutoramento do autor (Pereira, 2018b). 
A análise dessas dimensões se baseou, principalmente, em dados levantados com a realização de entrevistas com burocratas ativistas LGBT que atuaram nesses órgãos. Essas entrevistas também foram a principal fonte de informações utilizadas na consecução do segundo objetivo específico aqui mencionado - mapear as intervenções da chefia do Executivo nos órgãos analisados no período de abrangência da pesquisa.

Os informantes desta pesquisa foram mapeados a partir do método da indicação por "bola de neve". Foram realizadas entrevistas com ativistas LGBT que trabalharam ao longo desse período no MEC (duas entrevistas), no MinC (uma entrevista), no MS (uma entrevista) e na SDH (cinco entrevistas). A maioria dos informantes era formada por burocratas de médio escalão, sendo que apenas uma das entrevistadas ocupou posição de chefia no órgão ao qual esteve vinculada. Os vínculos dos informantes com a SDH e o MEC abrangeram o período entre o primeiro Governo Lula e o primeiro Governo Dilma. Já os vínculos dos informantes com o MinC e o MS abrangeram apenas o período entre o segundo Governo Lula e primeiro Governo Dilma, no qual ocorreram as principais transformações nos resultados políticos do ativismo institucional LGBT. As entrevistas tiveram seu conteúdo analisado buscando-se identificar semelhanças e diferenças entre os órgãos investigados no que se refere às dimensões citadas anteriormente.

Como é possível observar, a distribuição das entrevistas nos órgãos analisados não é equilibrada. Buscando superar essa lacuna do desenho metodológico da investigação, o material das entrevistas foi complementado por uma revisão da literatura que versa sobre a construção de políticas de diversidade e de direitos sexuais em cada um desses órgãos ao longo dos governos aqui analisados, em especial nos casos em que o número de entrevistas realizadas para a presente pesquisa foi menor. Foram priorizados artigos, dissertações e teses que apresentavam materiais de entrevistas realizadas com ativistas LGBT que atuaram nesses órgãos ao longo do período analisado, utilizadas como fontes secundárias para essa pesquisa empírica.

Por fim, para atingir o terceiro dos objetivos específicos desse trabalho foram utilizadas três fontes de dados. Em primeiro lugar, os informantes 
da pesquisa indicaram em suas entrevistas iniciativas do Governo Federal que responderam a demandas do movimento LGBT ao longo do período analisado. Em segundo lugar, foram utilizados dados já produzidos pelo Grupo Ser-Tão e por Aguião (2014) sobre as políticas LGBT no Brasil. Esses dois conjuntos de dados deram origem a um mapeamento de inciativas exclusivamente relacionadas a pessoas LGBT realizadas no âmbito do Governo Federal entre 2003 e 2014, identificando-se o órgão responsável por essas ações. Em terceiro lugar, foram utilizados dados do Portal da Transparência do Governo Federal buscando-se mapear os recursos destinados por este a ações de combate à homofobia e de defesa dos direitos LGBT entre 2004 e 2014 (os dados de 2003 não estavam disponíveis).

Foram realizados dois tipos de levantamento no Portal da Transparência. O primeiro buscou mapear os recursos federais transferidos para as organizações filiadas à Associação Brasileira de Lésbicas, Gays, Bissexuais, Travestis e Transexuais (ABGLT) por meio de qualquer ação governamental prevista no orçamento 9 . O segundo buscou mapear os recursos federais alocados a ações governamentais especificamente voltadas a pessoas LGBT transferidos para qualquer entidade (sociedade civil, estados ou municípios). Para identificar essas últimas ações, realizou-se uma busca por palavras-chave ${ }^{\mathbf{1 0}}$ nos Planos Plurianuais (PPA) e nas Leis Orçamentárias Anuais (LOA) em vigor ao longo do período de abrangência da pesquisa. Foram selecionadas ações que, em sua descrição, claramente tinham como público-alvo específico as pessoas LGBT. Os dados foram categorizados segundo o órgão de origem dos recursos transferidos e o ano da transferência.

Na próxima seção apresentam-se os resultados relacionados ao primeiro e ao terceiro dos objetivos específicos aqui mencionados. A seção seguinte apresenta os resultados relacionados ao segundo desses objetivos.

\footnotetext{
${ }^{9}$ Para essa busca, é necessário identificar o CNPJ de cada organização. Das 222 organizações listadas no site da ABGLT em outubro de 2016 (incluindo a própria ABGLT), foi encontrado o CNPJ de 198 organizações. As organizações não encontradas ou não possuem CNPJ ou a informação não foi encontrada pelo autor. O CNPJ de cada grupo foi confirmado com dados do site da Receita Federal.

${ }^{10}$ Foram buscadas as palavras e expressões: "homofobia", "gay", "diversidade", "gênero", "preconceito", "discriminação", "orientação", "centro de referência".
} 


\section{Heterogeneidade e semelhança no Poder Executivo}

Esta seção tem como objetivo apresentar e comparar a trajetória e as configurações das interações entre três ministérios e uma secretaria de governo e ativistas LGBT nos últimos anos no Brasil. Para cada caso, serão analisados: a) a trajetória de alinhamento de crenças e cooperação entre a burocracia e o movimento LGBT, examinando-se, ainda, a prevalência dos grupos de burocratas que mais fortemente cooperaram com esse movimento em cada um dos ministérios e na secretaria; b) a influência dos ativistas institucionais LGBT sobre as estruturas burocráticas utilizadas como pontos de acesso às instituições em cada um desses órgãos; e c) o apoio dado pelas chefias dos órgãos a essas estruturas burocráticas e às iniciativas de burocratas ativistas LGBT neles inseridos.

\section{Secretaria de Direitos Humanos}

Ao longo dos governos aqui analisados, a SDH representou uma mudança na trajetória das políticas federais de direitos humanos no Brasil. Se, até o início dos anos 2000, essas políticas estiveram focadas na agenda dos direitos civis e políticos, a partir do primeiro governo Lula passaram a priorizar a garantia dos direitos sociais de grupos específicos que foram vistos como especialmente vulneráveis à violação de seus direitos (Natalino et al., 2009). Dessa forma, a partir desse governo, as demandas do movimento LGBT - naquele momento enquadradas como demandas pela garantia de direitos civis e sociais de um grupo específico diante das ameaças da violência e da discriminação homofóbicas (Carrara, 2010; Pereira, 2017; Ramos; Carrara, 2006) - se alinharam a crenças de grupos emergentes e dominantes na SDH, fomentando-se relações de cooperação entre movimento e burocracia desde o início do primeiro governo Lula, apesar de relatos de resistências iniciais de parte da burocracia pelos entrevistados.

Essas resistências iniciais parecem ter retardado o processo de construção de estruturas burocráticas que servissem mais fortemente como pontos de acesso para ativistas LGBT na SDH. Apenas em 2009 foi criada 
a Coordenação Geral de Promoção da Cidadania LGBT (CGPCLGBT) liderada, em muitos momentos, por ativistas do movimento - e, em 2010, foi instaurado o Conselho Nacional de Combate à Discriminação de LGBT (CNCD/LBGT), que contou com a participação de ativistas do movimento. A partir daí, a SDH se tornou o único dos órgãos aqui apresentados a contar, no período em análise, com estruturas burocráticas exclusivamente ligadas a políticas LGBT. Por sua exclusividade temática, essas estruturas foram fortemente controladas pelo ativismo institucional LGBT.

Ao longo do período analisado, ativistas institucionais LGBT mencionaram ter recebido forte apoio da chefia da $\mathrm{SDH}$, embora tenham manifestado preferências pessoais por secretárias ou secretários específicos. Em seus relatos ao pesquisador, ativistas institucionais LGBT destacaram que, em determinados momentos de conflito, a chefia da secretaria se posicionou de forma contrária à chefia do Executivo.

\section{Ministério da Saúde}

Já no caso do MS, as demandas do movimento LGBT encontraram alinhamento com crenças historicamente dominantes nesse ministério e, assim, relações de cooperação entre esse movimento e a burocracia desse órgão remontam à década de 1990. Desde essa década, o movimento sanitarista brasileiro tem exercido forte influência sobre as políticas de saúde pública do governo federal, sugerindo que os agravos em saúde estão profundamente ligados às desigualdades existentes no que tange à garantia de direitos dos cidadãos. Dessa forma, as políticas públicas de saúde deveriam também oferecer soluções para problemas sociais como a discriminação e a desigualdade (Barata, 2009; Côrtes, 2009; Mattos, 2004; 2009). Assim, o MS foi o primeiro dos órgãos do Executivo federal a estabelecer cooperação com o movimento LGBT, já na década de 1990, no âmbito da política de combate à AIDS no Brasil, que tomou como um importante princípio o combate ao preconceito e à discriminação contra pessoas LGBT (Facchini, 2003; Galvão; Bastos; Nunn, 2012; Grangeiro; 
Silva; Teixeira, 2009; Paiva, 2013; Parker, 2003; Pereira; Nichiata, 2011; Ramos, 2004).

Mais recentemente, porém, as demandas do movimento LGBT na área da saúde se ampliaram para além do combate à AIDS, incluindo demandas como o acesso ao processo transexualizador no Sistema Único de Saúde (SUS) e a garantia de um atendimento não discriminatório nesse sistema. De acordo com a literatura sobre o tema, tais demandas foram recebidas com maior resistência pela burocracia desse ministério, fragilizando-se as relações de cooperação entre movimento e burocracia (Laurentino, 2015; Mello et al., 2011).

As principais estruturas burocráticas mencionadas em entrevista ao pesquisador e pela literatura como pontos de acesso para a defesa das demandas do movimento LGBT no MS foram o Departamento de DST, AIDS e Hepatites Virais (DDAHV), o Departamento de Apoio à Gestão Participativa (DAGEP) e o Comitê Técnico de Saúde LGBT (Laurentino, 2015). Porém, mesmo no interior dessas estruturas, uma informante desta pesquisa relatou resistências a determinadas demandas, tais como aquelas defendidas por travestis e transexuais. Assim, sua influência sobre essas estruturas burocráticas foi apenas moderada.

No que se refere ao apoio da chefia do MS às demandas do movimento LGBT, embora não relate resistências em momento anteriores, Laurentino (2015) destaca o apoio recebido por ativistas institucionais desse movimento ao longo da gestão de Alexandre Padilha, entre os anos de 2011 e 2014, no processo de construção e aprovação da Política Nacional de Saúde Integral de LGBT. O autor, porém, destaca a eventual oposição de membros de órgãos com poder de decisão nesse ministério a essa política, tais como o Conselho Nacional de Saúde (CNS) e a Comissão Intergestores Tripartite (CIT). Em relato ao pesquisador, uma burocrata ativista LGBT destacou ainda uma diminuição do apoio da chefia do ministério, a partir de mudanças realizadas em 2014. 


\section{Ministério da Cultura}

Já no que se refere ao MinC, as políticas culturais desenvolvidas e implementadas ao longo dos governos aqui analisados se afastaram de políticas anteriores em ao menos três sentidos. Primeiro, buscaram romper com a descontinuidade das políticas culturais e com o protagonismo da iniciativa privada nesse setor, por meio da criação de um Sistema Nacional de Cultura (Barbalho, 2007; 2014; Barbosa; Ellery; Midlej, 2009; Bezerra; Barbalho, 2015; Rubim, 2010). Em segundo lugar, opuseram-se ao foco no fomento a áreas consagradas e eruditas da produção artística, mobilizando um conceito "antropológico" de cultura, que também a toma como uma forma de expressão simbólica cuja realização é um pressuposto da cidadania (Barbosa; Ellery; Midlej, 2009; Bezerra; Barbalho, 2015; Lacerda; Marques; Rocha, 2010; Rubim, 2010; Santos et al. 2010). Em terceiro lugar, opuseramse à ideia de construção de uma identidade nacional por meio de um processo de miscigenação que secundariza as diferenças culturais, a partir de políticas que valorizavam a diversidade da cultura brasileira, fomentando, em especial, expressões culturais de grupos marginalizados pelo Estado e pelo mercado (Barbalho, 2007; Barros; Ziviane, 2011; Bezerra; Barbalho, 2015; Santos et al. 2010).

Assim, as políticas culturais dos governos petistas tiveram dois focos: a construção e implementação de um Sistema Nacional de Cultura e o fomento a expressões da diversidade cultural brasileira. De acordo com Barbalho (2014), esses projetos eram defendidos com maior veemência por diferentes grupos, sendo que o segundo deles destacou-se durante os dois governos Lula, nas gestões de Gilberto Gil e Juca Ferreira, e o primeiro teria ganhado maior destaque a partir do primeiro governo Dilma, nas gestões de Anna de Holanda e Martha Suplicy. É em relação ao segundo desses projetos que as demandas do movimento LGBT se alinhavam mais fortemente, pois pessoas LGBT eram vistas como um dos grupos sociais cujas expressões culturais foram historicamente marginalizadas. Nesse sentido, as crenças de ativistas LGBT e da burocracia do MinC estiveram 
mais alinhadas ao longo dos governos Lula, ampliando-se nesse período a cooperação entre esses atores.

O histórico dos pontos de acesso encontrados por esse movimento nesse órgão e do apoio da chefia desse ministério às iniciativas de ativistas institucionais LGBT seguem a mesma trajetória. Duas secretarias foram os principais pontos de acesso encontrados pelo movimento LGBT ao longo dos governos aqui analisados, a Secretaria da Identidade e da Diversidade Cultural (SID) e a Secretaria da Cidadania Cultural (SCC), ambas envolvidas em políticas de fomento à diversidade cultural brasileira (Barros; Ziviane, 2011; Bezerra; Barbalho, 2015; Lacerda; Rocha, 2010; Santos et al., 2010)11. Em 2011, essas secretarias foram fundidas, sendo criada a Secretaria de Cidadania e Diversidade Cultural (SCD). Esse processo diminuiu o controle dos ativistas institucionais LGBT sobre as estruturas burocráticas por eles utilizadas como pontos de acesso ao MinC.

Ademais, a literatura indica que mudanças na chefia do ministério a partir do primeiro governo Dilma teriam enfraquecido a força da recémcriada SCD em relação às demais secretarias do órgão, já que as novas gestões teriam estabelecido como prioridade a construção de um Sistema Nacional de Cultura (Barbalho, 2014). Assim, a partir de 2011, além de perderem um de seus espaços de articulação interna, ativistas institucionais LGBT também teriam perdido espaços na hierarquia mais ampla do MinC e apoio de sua chefia.

\footnotetext{
${ }^{11}$ A SID foi responsável pelo Programa Identidade e Diversidade Cultural (Brasil Plural), que transferiu recursos federais para projetos relacionados à diversidade cultural brasileira. Já a SCC foi responsável pela criação dos chamados Pontos de Cultura, que incentivaram organizações e comunidades tradicionais que desenvolviam atividades culturais. Cabe ressaltar que, enquanto as políticas desenvolvidas pela SID estabeleceram um públicoalvo mais específico - incluindo editais especiais para a cultura LGBT -, as políticas da SCC tinham um público mais amplo, que incluía a população de baixa renda, estudantes do ensino básico e comunidades rurais, indígenas e quilombolas (Barros; Ziviane, 2011; Bezerra; Barbalho, 2015; Lacerda; Rocha, 2010; Santos et al., 2010).
} 


\section{Ministério da Educação}

Por fim, no caso do MEC, a literatura indica que as principais disputas em torno das políticas educacionais brasileiras nos últimos anos ocorreram entre, de um lado, grupos que estabeleceram maior foco nos resultados da educação formal por meio do estabelecimento de metas claras para o desempenho escolar e, de outro, grupos que estabeleceram foco nos processos de ensino e aprendizagem, enfatizando a defesa da gestão democrática da educação e o combate às desigualdades sociais (Simielli, 2013). As demandas do movimento LGBT se alinharam mais fortemente à segunda dessas perspectivas, pois defendiam que a garantia do direito à educação das pessoas LGBT pressupõe a garantia dos demais direitos desses indivíduos. Assim, políticas de combate à violência e à discriminação homofóbicas na escola seriam essenciais para a consolidação da cidadania LGBT. Porém, como os grupos que defendem essa posição não foram dominantes no MEC ao longo do período analisado, as relações de cooperação entre o movimento LGBT e esse ministério encontraram obstáculos, segundo relatos de entrevistas a esta pesquisa e na literatura.

O principal ponto de acesso encontrado por ativistas institucionais LGBT para a defesa dessas crenças foi, naquele período, a Secretaria de Educação Continuada, Alfabetização e Diversidade (SECAD), criada 2004 em torno da ideia de que a garantia do direito à educação pressupõe a garantia dos direitos humanos como um todo e o respeito à diversidade cultural (Carreira, 2015; Daniliauskas, 2011; Fernandes, 2011) ${ }^{\mathbf{1 2}}$. Porém, relatos da literatura e dos informantes desta pesquisa indicam que ativistas institucionais LGBT encontraram obstáculos internos mesmo contando com esse ponto de acesso.

Tais relatos sugerem que, por um lado, membros de outras secretarias vinculadas a esse ministério apresentaram resistências em relação às políticas

\footnotetext{
${ }^{12} \mathrm{Em}$ entrevistas ao pesquisador, também foi mencionada a atuação da Secretaria de Educação Básica (SEB) no projeto "Saúde e Prevenção nas Escolas". A literatura destaca também a importância do grupo de trabalho para acompanhamento das ações do Programa Brasil sem Homofobia no MEC (Fernandes, 2011).
} 
da SECAD, tornando-a secundária na estrutura do MEC. Por outro lado, mesmo dentro dessa secretaria, as pautas LGBT teriam sido secundárias, destacando-se o baixo número de burocratas envolvidos na implementação de políticas de diversidade sexual. Por fim, em 2011, a SECAD foi fundida à Secretaria de Educação Especial (SEESP), originando a Secretaria de Educação Continuada, Alfabetização, Diversidade e Inclusão (SECADI). De acordo com um informante desta pesquisa, alguns dos antigos membros da SEESP apresentavam resistências claras às demandas do movimento LGBT no MEC. Dessa maneira, a fusão teria debilitado ainda mais o principal ponto de acesso utilizado por ativistas institucionais LGBT no MEC, já pouco controlado por eles em momentos anteriores.

O apoio dado pela chefia do ministério a políticas de garantia dos direitos LGBT no MEC também teria sido inconstante. De acordo com Carreira (2015), esta temática conquistou maior espaço no ministério na gestão de Tarso Genro, entre 2004 e 2005, com a criação da SECAD. No que se refere à gestão de Fernando Haddad, entre 2005 e 2012, por um lado, destaca-se, nesse período, a realização da maior parte das iniciativas do MEC relacionadas a pessoas LGBT aqui mapeadas. Por outro lado, entrevistados demandaram um posicionamento público mais forte da chefia do ministério em episódios públicos de confronto em torno dessa temática, tal como o narrado na introdução deste artigo. De acordo com Carreira (2015), em especial a partir do início do primeiro Governo Dilma em 2011, a chefia do MEC teria optado pela estratégia da "ação silenciosa" em torno de temas relacionados à diversidade, estratégia mantida pela gestão posterior à de Fernando Haddad.

\section{Trajetórias e encaixes distintos, resultados semelhantes}

Por meio dessas análises é possível identificar que SDH, MS, MinC e MEC apresentam distintas trajetórias e configurações de suas interações com o movimento LGBT (Quadro 1). Na SDH, o ativismo institucional LGBT encontrou condições constantemente favoráveis ao longo do período 
em análise. No polo oposto, as condições encontradas no MEC foram constantemente as menos favoráveis dentre as analisadas. No caso do MS, devido ao apoio reforçado da chefia do ministério a partir de 2011, condições mais favoráveis foram encontradas no primeiro Governo Dilma. No MinC, ao contrário, devido a trocas na chefia desse ministério e a mudanças organizacionais, condições mais favoráveis ao ativismo LGBT foram encontradas ao longo dos governos Lula.

Quadro 1 - Trajetórias e características das relações e encaixes Institucionais entre o ativismo institucional LGBT e SDH, MS, MinC e MEC entre 2003 e 2014

\begin{tabular}{|c|c|c|c|}
\hline & $\begin{array}{c}\text { Trajetória do alinhamento } \\
\text { de crenças e da cooperação } \\
\text { entre o movimento LGBT e } \\
\text { grupos influentes nos órgãos } \\
\text { analisados }\end{array}$ & $\begin{array}{c}\text { Influência } \\
\text { dos ativistas } \\
\text { institucionais LGBT } \\
\text { sobre seus pontos } \\
\text { de acesso aos órgãos } \\
\text { analisados }\end{array}$ & $\begin{array}{l}\text { Apoio da chefia do } \\
\text { órgão ao ativismo } \\
\text { institucional LGBT }\end{array}$ \\
\hline $\mathrm{SDH}$ & $\begin{array}{l}\text { Alinhamento de crenças e } \\
\text { cooperação recente com } \\
\text { grupos emergentes dominantes } \\
\text { na secretaria }\end{array}$ & $\begin{array}{l}\text { CGPCLGBT e CNCD/ } \\
\text { LGBT: influência forte }\end{array}$ & Apoio constante \\
\hline MS & $\begin{array}{l}\text { Alinhamento de crenças e } \\
\text { cooperação de longa data } \\
\text { com grupos historicamente } \\
\text { dominantes no ministério }\end{array}$ & $\begin{array}{l}\text { DDAHV e DAGEP: } \\
\text { influência moderada }\end{array}$ & $\begin{array}{l}\text { Apoio instável, } \\
\text { fortalecido entre } \\
2011 \text { e fevereiro de } \\
2014\end{array}$ \\
\hline MinC & $\begin{array}{l}\text { Alinhamento de crenças e } \\
\text { cooperação recente com } \\
\text { grupos emergentes no } \\
\text { ministério: dominantes entre } \\
2003 \text { e } 2010 \text { e secundários } \\
\text { entre } 2011 \text { e } 2014\end{array}$ & $\begin{array}{l}\text { SID (2003-2010): } \\
\text { influência forte } \\
\text { SCC (2003-2010): } \\
\text { influência moderada } \\
\text { SCD (2011-2014): } \\
\text { influência moderada }\end{array}$ & $\begin{array}{l}\text { Apoio instável, } \\
\text { fortalecido entre } \\
2003 \text { e } 2010\end{array}$ \\
\hline MEC & $\begin{array}{l}\text { Alinhamento de crenças } \\
\text { e cooperação recente } \\
\text { com grupos emergentes } \\
\text { e secundários dentro do } \\
\text { ministério }\end{array}$ & $\begin{array}{l}\text { SECAD (2003-2010): } \\
\text { influência moderada } \\
\text { SECADI (2011-2014): } \\
\text { influência fraca }\end{array}$ & Apoio incerto \\
\hline
\end{tabular}

Fonte: adaptado de Pereira (2018b). 
Apesar de terem construído relações com o ativismo LGBT marcadas por trajetórias e configurações distintas, os órgãos aqui analisados apresentam variações semelhantes nos resultados obtidos por ativistas institucionais desse movimento. Primeiramente, apresentam resultados constantes no que se refere às iniciativas federais exclusivamente relacionadas às pessoas LGBT (Figura 1). Uma exceção pode ser observada no caso da SDH, que apresenta uma intensificação nessas ações entre 2011 e 2013. Considerando-se o quadro geral, no entanto, observa-se uma intensificação dessas iniciativas entre 2008 e 2011 e uma queda entre 2012 e 2013.

Figura 1- Iniciativas do Poder Executivo Federal exclusivamente direcionadas a pessoas

LGBT e suas demandas, por órgão responsável pela iniciativa (2004-2014)

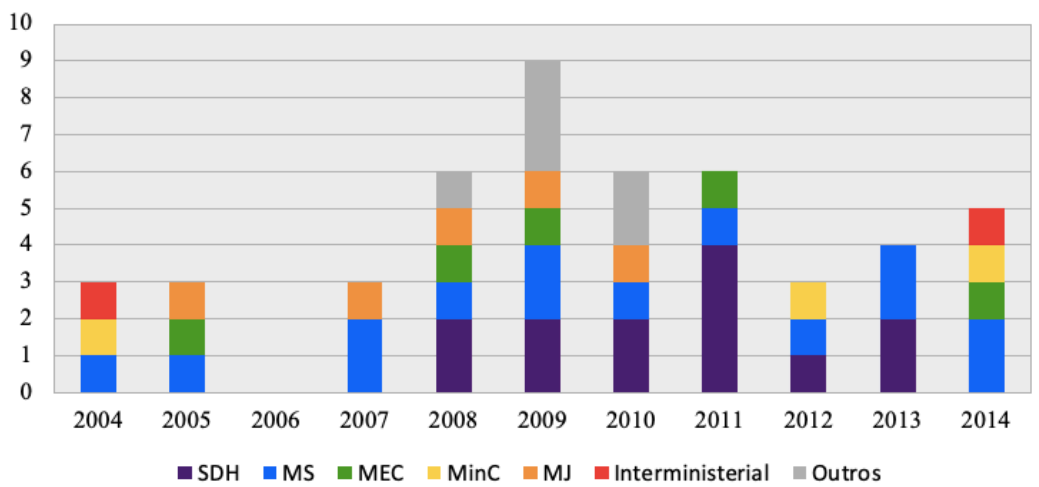

Fonte: Pereira (2018b), com dados da pesquisa empírica, de Grupo Ser-Tão e de Aguião (2014).

Em segundo lugar, é possível observar uma queda no volume de recursos federais transferidos a organizações filiadas à ABGLT e no volume de recursos federais transferidos por meio de ações governamentais exclusivamente relacionadas a pessoas LGBT, a partir de 2011, em três dos órgãos analisados (Figuras 2 e 3). A exceção é o MS, que apresenta um crescimento no 
volume de recursos transferidos a organizações filiadas à ABGLT em 2014, conforme apresentado na Figura 2.

Figura 2 - Volume de recursos federais (em reais) transferidos a organizações filiadas à ABGLT por ano e por órgão de origem dos recursos (2004-2014)

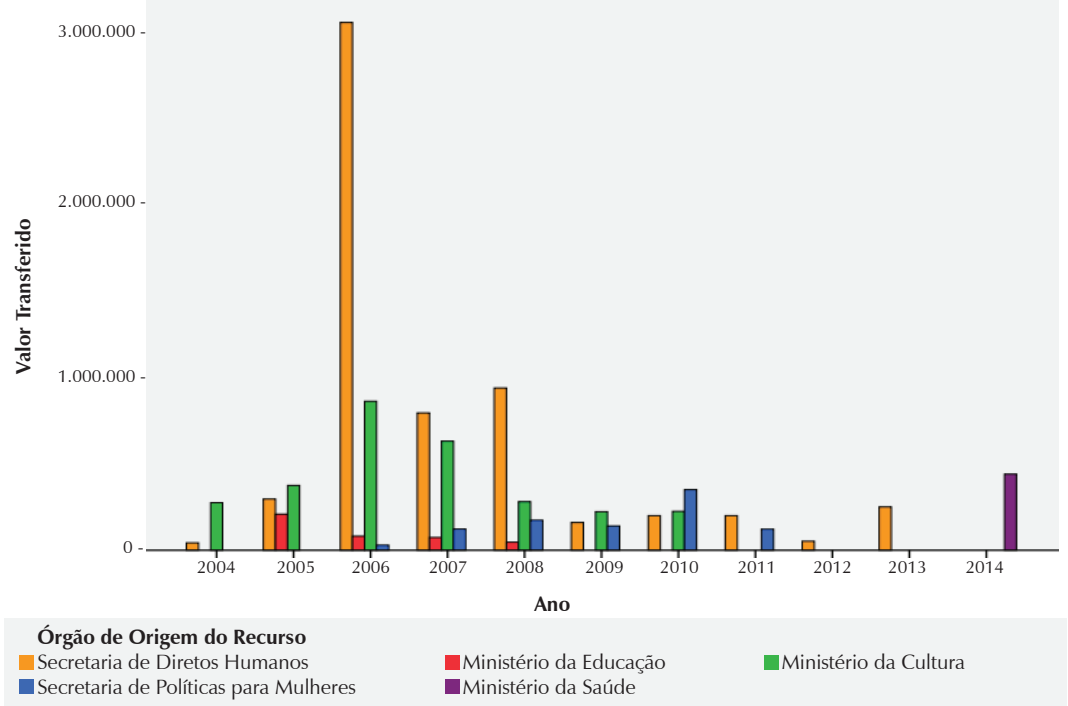

Fonte: Pereira (2018b) com dados do Portal da Transparência.

Indo ao encontro das expectativas da recente literatura brasileira sobre as relações entre Estado e movimentos sociais, as particularidades das interações socioestatais e dos encaixes institucionais encontrados por ativistas institucionais LGBT em cada um desses órgãos ajudam a compreender parte desses resultados. As condições favoráveis encontradas por eles na SDH ajudam a compreender os motivos pelos quais esse é o órgão que mais transferiu recursos por meio de ações relacionadas a pessoas LGBT, apesar de ser aquele com menor orçamento dentre os analisados. As condições desfavoráveis encontradas de forma constante por esses ativistas no MEC podem ser um dos motivos pelos quais nesse órgão é observado 
um número menor de iniciativas e transferências. A formalização dos pontos de acesso desses ativistas institucionais na SDH também ajuda a explicar a ampliação no número de iniciativas desse órgão a partir de 2009. Por fim, o fortalecimento do apoio da chefia do MS a partir de 2011 pode ser um fator importante para explicar sua trajetória atípica.

Figura 3 - Volume de recursos federais (em reais) transferidos por meio de ações governamentais exclusivamente relacionadas a pessoas LGBT e suas demandas por ano e por órgão de origem dos recursos (2006-2014)

5.000 .000

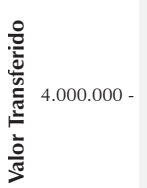

$3.000 .000-$

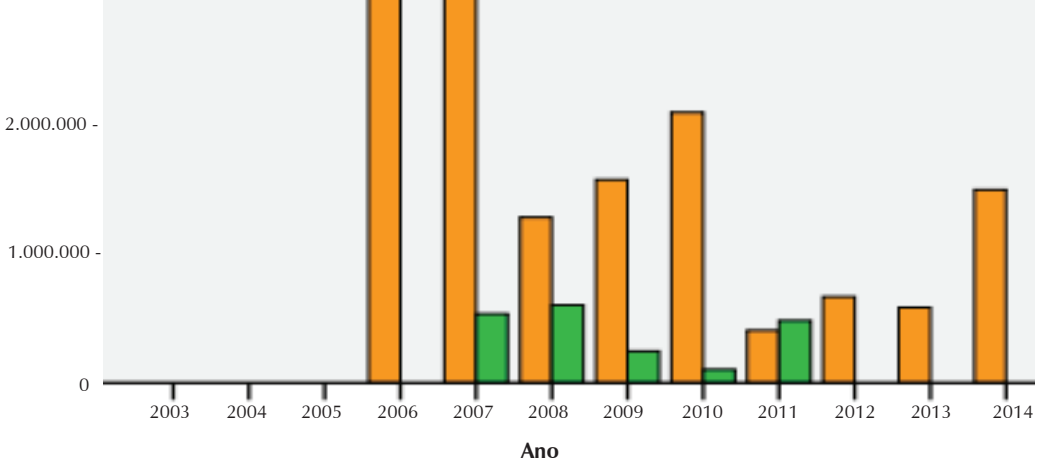

Fonte: Pereira (2018b) com dados do Portal da Transparência.

Porém, os períodos de ampliação e retração nas transferências dos recursos federais aqui analisados são compartilhados por órgãos que 
apresentam trajetórias e configurações distintas em suas relações com ativistas institucionais LGBT. A queda nessas transferências a partir do primeiro Governo Dilma se articula à trajetória do MinC, órgão no qual melhores condições para burocratas ativistas LGBT foram encontradas ao longo dos governos Lula. No entanto, essa mesma queda também pode ser observada nos casos da SDH e do MEC, nos quais essas condições se mantiveram estáveis ao longo do período analisado, constantemente favoráveis no primeiro desses órgãos e constantemente desfavoráveis no segundo deles. Busco demonstrar, ao longo da próxima seção, que essas variações concomitantes podem ser explicadas pelas intervenções realizadas pela chefia do Executivo em seus ministérios e secretarias, que foram semelhantes nos quatro órgãos aqui analisados.

\section{A chefia do Executivo e o ativismo institucional LGBT}

Neste trabalho, argumento que a dinâmica geral de queda nos resultados obtidos por ativistas institucionais LGBT entre 2003 e 2014 pode ser explicada pelas intervenções realizadas pela chefia do Executivo em seus ministérios e secretarias a partir do governo Dilma. Nesta seção, busco identificar essas intervenções e seus impactos sobre o ativismo institucional LGBT.

Em primeiro lugar, conforme já destacado na seção anterior, a chefia do Executivo impôs obstáculos organizacionais aos burocratas ativistas LGBT a partir de 2011, ao fundir as secretarias nas quais sua influência era mais proeminente a outras estruturas burocráticas no MinC e no MEC. Em ambos os casos, de acordo com os entrevistados, as secretarias resultantes da fusão passaram a ser mais fortemente controladas por membros dos órgãos aos quais ativistas LGBT tinham menos acesso, criando obstáculos para sua articulação interna.

Cabe ressaltar que as dificuldades impostas por essas fusões foram avaliadas de formas distintas por entrevistados vinculados a diferentes ministérios. No caso do MinC, a avaliação desse processo é avaliada menos 
negativamente, na medida em que existia certo alinhamento de crenças entre membros dominantes nas duas secretarias fundidas. Já no caso do MEC esse alinhamento inexistia e, assim, a fusão entre a SECAD e a SEESP foi avaliada de forma mais fortemente negativa pelo principal informante nesta pesquisa, vinculado à primeira dessas secretarias. Porém, nos dois casos, as fusões tiveram como impacto sobre o ativismo institucional LGBT a fragilização de seus encaixes institucionais e de sua capacidade de ação nesses órgãos, em decorrência da diminuição dos pontos de acesso disponíveis.

Em segundo lugar, a chefia do Executivo também impôs obstáculos orçamentários à ação de burocratas ativistas LGBT. O primeiro desses obstáculos esteve relacionado à liberação de emendas parlamentares dedicadas a ações de defesa dos direitos sexuais e de combate à homofobia. Ao longo do primeiro governo Lula, o valor total das transferências efetivamente realizadas no âmbito de ações orçamentárias exclusivamente relacionadas a questões LGBT superou o valor inicialmente previsto para essas ações nos projetos de lei orçamentária em dois anos, totalizando-se um acréscimo de aproximadamente 1,23 milhões de reais na soma desses anos. Já ao longo do primeiro governo Dilma, isso ocorreu apenas em um ano, totalizando-se um acréscimo de aproximadamente 0,76 milhões de reais. Isso ocorreu apesar de um volume maior de recursos ter sido adicionado a essas rubricas por meio de emendas parlamentares ao longo do primeiro Governo Dilma, havendo um crescimento de aproximadamente 15,3 milhões de reais para aproximadamente 21,1 milhões de reais em emendas parlamentares em relação ao governo anterior.

Em relação a esse ponto, é importante destacar que as emendas parlamentares foram uma das principais estratégias utilizadas por organizações do movimento LGBT para financiar políticas de combate à homofobia e garantia de direitos sexuais nesse período, na medida em que ativistas avaliaram que os recursos inicialmente destinados pelo Executivo em seus projetos de lei orçamentária eram insuficientes. A ABGLT, por exemplo, desenvolveu nesse período o que denominou de "Projeto Aliadas" de influência política sobre o Legislativo federal. Assim, o contingenciamento 
de emendas parlamentares teve um importante impacto sobre os recursos disponíveis para políticas LGBT no período.

Um segundo obstáculo orçamentário encontrado por ativistas institucionais LGBT ao longo do primeiro Governo Dilma esteve relacionado ao desenho do orçamento. A partir de 2012, o orçamento público passou a ser desenhado a partir de rubricas mais gerais para a alocação de recursos. Comparando-se o período entre 2008 e 2011 e o período entre 2012 e 2015, observa-se uma queda de quatro para uma ação orçamentária vinculada de forma específica a questões LGBT. Isso significa que, a partir do Plano Plurianual (PPA) 2012-2015, ativistas LGBT passaram a disputar recursos relacionados a rubricas orçamentárias mais gerais com ativistas de outros movimentos sociais relacionados a "pautas da diversidade", dificultando seu acesso a recursos públicos.

Em terceiro lugar, a chefia do Executivo passou a emitir sinais públicos de que não daria mais suporte aberto a iniciativas de burocratas ativistas LGBT. Um exemplo desse tipo de sinal foi a declaração da presidenta Dilma no caso narrado na introdução deste artigo. Os impactos desse episódio foram destacados até mesmo por ativistas institucionais LGBT ligados à SDH, órgão que apresentou condições mais favoráveis a esses ativistas ao longo do período analisado. Um informante vinculado a essa secretaria, por exemplo, avalia que, com essa declaração pública relacionada ao MEC, o governo "sinalizou para os outros ministérios que aquele era um assunto com o qual se tinha que ter muito cuidado" e que "esse tema deveria ser engavetado", complementando: "[e]ntão, muita coisa travou a partir dali".

Por fim, mesmo quando ativistas institucionais superaram esses eventuais obstáculos organizacionais, orçamentários e simbólicos, a chefia do Executivo vetou suas iniciativas em ao menos dois casos, ambos narrados na introdução deste artigo. O primeiro deles foi o veto à distribuição do material didático desenvolvido no âmbito do projeto Escola sem Homofobia. O segundo ocorreu em 2012, no MS, em relação a uma campanha de prevenção 
às DST no Carnaval daquele $a^{13}{ }^{13}$. $\mathrm{O}$ veto presidencial tem profundos impactos sobre os resultados do ativismo institucional. Além do impacto mais evidente de impedir que as ações desses ativistas se transformem efetivamente em políticas públicas, o veto presidencial também desestimula a ação ao diminuir o sentimento de eficácia entre os ativistas institucionais.

Em relação a esses últimos dois pontos, é importante destacar que as ações da chefia do Executivo foram precedidas por uma forte mobilização da Frente Parlamentar Evangélica (FPE), cujos membros se tornaram mais mobilizados e presentes nas coalizões dos governos petistas a partir do primeiro governo Dilma. Por exemplo, no caso do veto à distribuição do material didático vinculado ao programa Escola sem Homofobia, parlamentares evangélicos conservadores e seus aliados apresentaram, em momentos distintos, duas ameaças à chefia do Poder Executivo, caso intervenções nessa política não fossem realizadas. Ameaçaram trancar a pauta de votações do plenário da Câmara dos Deputados, impedindo a tramitação de projetos relevantes para o Executivo federal e, em outra ocasião, ameaçaram convocar para prestar depoimento a uma Comissão Parlamentar de Inquérito o então ministro da Casa-Civil Antônio Palocci, alvo de denúncias de enriquecimento ilícito pela imprensa (Pereira, 2018b). Assim, ainda que mais evidentes nos casos da sinalização de fechamento de oportunidades e dos vetos presidenciais, a pressão desses parlamentares parece ter motivado, ao menos em parte, as crescentes intervenções da chefia do Executivo nas políticas LGBT produzidas por burocratas ativistas desse movimento.

O Quadro 2 sistematiza essas intervenções, de acordo com os órgãos que as sofreram, possibilitando concluir que, embora não tenham sofrido exatamente as mesmas intervenções, ativistas institucionais LGBT que estiveram vinculados a diversos ministérios e secretarias sofreram pressões semelhantes da chefia do Executivo, as quais impuseram obstáculos comuns

\footnotetext{
${ }^{13} \mathrm{Na}$ ocasião, o ministro Alexandre Padilha negou a existência de tal veto, alegando que a peça publicitária não teria sido feita para ser transmitida publicamente. No entanto, de acordo com relatos dados em entrevistas ao pesquisador, os vídeos teriam sido vetados pela presidenta Dilma após pressões da FPE.
} 
à sua ação. Obstáculos organizacionais foram impostos principalmente nos casos do MEC e do MinC, por meio da fusão de secretarias. Obstáculos orçamentários afetaram ativistas inseridos em todos os órgãos aqui analisados. Apesar de direcionados especificamente a uma iniciativa do MEC, é possível supor que obstáculos simbólicos também afetam o ativismo institucional em diversos órgãos, já que as declarações públicas da presidência fizeram referência a todos os órgãos da burocracia do Executivo federal e vieram ao conhecimento de burocratas ativistas inseridos em diferentes ministérios e secretarias. Por fim, iniciativas do MEC e do MS foram alvo de vetos presidenciais. Argumento aqui que, por esse motivo, tais órgãos apresentaram uma oscilação similar nos resultados obtidos por burocratas ativistas LGBT a partir do primeiro Governo Dilma.

Quadro 2 - Tipos de intervenção da chefia do Executivo por órgão afetado ao longo do primeiro Governo Dilma

\begin{tabular}{|l|l|}
\hline \multicolumn{1}{|c|}{ Tipo de intervenção da chefia do Executivo } & \multicolumn{1}{c|}{ Órgão afetado } \\
\hline $\begin{array}{l}\text { Imposição de Obstáculos Organizacionais (fusão de } \\
\text { secretarias) }\end{array}$ & MinC e MEC \\
\hline $\begin{array}{l}\text { Imposição de Obstáculos Orçamentários (liberação de } \\
\text { emendas e desenho do orçamento) }\end{array}$ & SDH, MS, MinC e MEC \\
\hline $\begin{array}{l}\text { Imposição de Obstáculos Simbólicos (declarações } \\
\text { públicas da presidência) }\end{array}$ & SDH, MS, MinC e MEC \\
\hline Veto Presidencial & MS e MEC. \\
\hline
\end{tabular}

Fonte: Adaptado de Pereira (2018b).

Essas diversas intervenções realizadas pela chefia do Executivo, a partir do primeiro governo Dilma, na burocracia a ela subordinada tiveram impactos sobre as ações de ativistas institucionais inseridos em diferentes órgãos do Executivo federal, diminuindo sua capacidade de influenciar as políticas públicas neles desenvolvidas. Dessa forma, a partir dos dados analisados nesta seção, sugiro que os resultados do ativismo institucional são, ao menos em parte, influenciados por ações e decisões governamentais 
que superam a esfera específica dos ministérios e secretarias, na qual buscam ser produzidos.

\section{Considerações finais: movimentos sociais, governos e oportunidades políticas}

Neste artigo, argumentei que, para apreender de forma mais complexa os limites e as possibilidades do ativismo institucional, é necessário "trazer os governos de volta", não tomando o Estado como uma "colcha de retalhos" de instituições e órgãos completamente autônomos, mas como uma heterogeneidade gerenciada pela chefia do Executivo a partir dos conflitos existentes entre os seus projetos políticos, os projetos da burocracia estatal e os dos membros da coalizão governante. No caso em análise, busquei demonstrar que as variações nos resultados obtidos por ativistas institucionais LGBT em diferentes órgãos do Executivo federal, entre 2003 e 2014, é apenas parcialmente explicada pelas peculiaridades de cada um desses ministérios e secretarias. Para explicar a dinâmica mais ampla de ascensão e queda dos resultados produzidos por esses ativistas nesse período, é necessário compreender como a chefia do Executivo passou a impor obstáculos de diversas naturezas a suas ações, a partir do primeiro Governo Dilma.

A mudança na postura da chefia do Executivo em relação a essa temática foi possivelmente influenciada, em parte, por transformações na composição de sua coalizão de governo, que passou a contar com um número maior de membros do principal grupo antagonista do movimento LGBT no Congresso Nacional, a Frente Parlamentar Evangélica (FPE) (Pereira 2018a). Assim, algumas das atitudes tomadas pela presidência descritas na seção anterior desse trabalho foram precedidas por uma intensa mobilização e pressão dessa frente parlamentar em oposição a políticas LGBT, tal como no episódio do veto ao material didático produzido no âmbito do programa Escola sem Homofobia. 
Esses achados resgatam, em parte, uma importante agenda de pesquisa colocada pelo conceito de "oportunidades políticas" (Tarrow, 2009) no estudo de movimentos sociais: a análise dos impactos que mudanças em regimes e governos promovem sobre o surgimento, o desenvolvimento e os resultados da mobilização coletiva. Sugiro, assim, que a pertinência desse conceito não deve ser descartada, desde que - conforme tem sido indicado pela literatura brasileira recente sobre o tema (Pereira, 2018b; Abers; Silva; Tatagiba, 2018) - tal conceito seja repensado a partir de uma perspectiva relacional, que tome oportunidades políticas não apenas como um mero contexto no qual ocorre a ação de movimentos sociais, mas como o conjunto de ações e processos presentes nas relações estabelecidas entre movimentos sociais, instituições políticas e seus atores, que criam obstáculos ou facilitam a ação de movimentos sociais ou sinalizam fazê-lo. Nesse sentido, é necessário que pesquisas empíricas identifiquem quais ações e processos específicos presentes nas relações entre movimentos sociais e determinadas instituições políticas e seus atores afetam quais aspectos específicos da mobilização coletiva. A partir desse objetivo, busquei destacar, neste e em outros trabalhos, um conjunto de ações e processos relativos às relações estabelecidas entre movimentos sociais e governos que afetam as possibilidades de os primeiros influenciarem políticas públicas por meio do ativismo institucional, tais como os processos de gerenciamento de coalizões de governo e da burocracia estatal (Pereira, 2018a; 2018b).

Matheus Mazzilli Pereira é Doutor em Sociologia e professor do Programa de PósGraduação em Sociologia Política da Universidade Vila Velha.

$\doteq$ matheus.mazzilli@gmail.com 


\section{Referências}

1. ABERS, Rebecca. Ativismo na burocracia? O médio escalão do Programa Bolsa Verde. In: CAVALCANTE, Pedro; LOTTA, Gabriela (Orgs.). Burocracia de médio escalão: perfil, trajetória e atuação. Brasília: Enap, 2015. p. 143-175.

2. ABERS, Rebecca. Bureaucratic activism: pursuing environmentalism inside Brazilian State. Latin American Politics and Society, v. 61, n. 2, p. 21-44, 2019.

3. ABERS, Rebecca; SERAFIM, Lizandra; TATAGIBA, Luciana. Repertórios de interação Estado-Sociedade em um estado heterogêneo: a experiência na era Lula. Dados, v. 57, n. 2, p. 325-357, 2014. http://dx.doi.org/10.1590/00115258201411

4. ABERS, Rebecca; SILVA, Marcelo K.; TATAGIBA, Luciana. Movimentos sociais e políticas públicas: repensando atores e oportunidades políticas. Lua Nova, n. 105, p. 15-46, 2018. http://dx.doi.org/10.1590/0102-015046/105

5. ABERS, Rebecca; VON BÜLLOW, Marisa. Movimentos sociais na teoria e na prática: como estudar o ativismo através da fronteira entre Estado e sociedade? Sociologias, v. 13, n. 28, p. 52-84, 2011. http://dx.doi.org/10.1590/S151745222011000300004

6. AGÊNCIA BRASIL. Dilma diz que governo não fará "propaganda de opções sexuais". Agência Brasil - Folha de São Paulo [online], 26 mai. 2011. Disponível em: http://www1.folha.uol.com.br/cotidiano/2011/05/921243-dilma-diz-quegoverno-nao-fara-propaganda-de-opcoes-sexuais.shtml.

7. AGUIÃO, Sílvia. Fazer-se no "Estado": uma etnografia sobre o processo de constituição dos "LGBT" como sujeitos de direito no Brasil contemporâneo, 2014. Tese (Doutorado em Ciências Sociais). Instituto de Filosofia e Ciências Humanas, Universidade Estadual de Campinas, Campinas, 2014.

8. ALBUQUERQUE, Maria do Carmo A. O movimento pelos direitos da criança e do adolescente e o controle social sobre a política socioeducativa: repertórios de interação socioestatal. Política \& Sociedade, v. 14, n. 29, p. 31-66, 2015. https://doi.org/10.5007/2175-7984.2015v14n29p31

9. BANASZAK, Lee A. Inside and outside the State: movement insider status, tactics, and public policy achievements. In: MEYER, David S.; JENNESS, Valerie; INGRAM, Helen (Orgs.). Routing the opposition: social movements, public policy and democracy. Minneapolis: University of Minnesota Press, 2005. p. 149-176.

10. BANASZAK, Lee A. Moving feminist activists inside the American State: the rise of a state-movement intersection and its effects on state policy. In: JACOBS, Lawrence; KING, Desmond (Orgs.). The unsustainable American State. Oxford: Oxford University Press, 2009. p. 223-254.

11. BARATA, Rita B. Como e por que as desigualdades sociais fazem mal à saúde [online]. Rio de Janeiro: FIOCRUZ, 2009.

12. BARBALHO, Alexandre. Políticas culturais no Brasil: identidade e diversidade sem diferença. Trabalho apresentado no III Encontro de Estudos Multidisciplinares em Cultura, Salvador, 2007. 
13. BARBALHO, Alexandre. O Sistema Nacional de Cultura no governo Dilma: continuidades e avanços. Revista Lusófona de Estudos Culturais, v. 2, n. 2, p. 188-207, 2014. https://doi.org/10.21814/rlec.74

14. BARBOSA, Frederico; ELLERY, Herton; MIDLEJ, Suylan. A Constituição e a democracia cultural. Políticas Sociais: acompanhamento e análise, v. 2, n. 17, p. 225-281, 2009. Disponível em: http://repositorio.ipea.gov.br/handle/11058/4336.

15. BARCELOS, Márcio; SILVA, Marcelo K.; PEREIRA, Matheus M. Redes, campos, coalizões e comunidades: conectando movimentos sociais e políticas públicas. BIB, n. 82, p. 13-40, 2016. Disponível em: http://anpocs.org/index. php/bib-pt/bib-82/10589-redes-campos-coalizoes-e-comunidades-conectandomovimentos-sociais-e-politicas-publicas/file

16. BARROS, José M.; ZIVIANE, Paula. O programa cultura viva e a diversidade cultural. In: BARBOSA, Frederico; CALABRE, Lia (Orgs.). Pontos de Cultura: olhares sobre o programa Cultura Viva. Brasília: Ipea, 2011. p. 61-88.

17. BEZERRA, Jocastra; BARBALHO, Alexandre. As culturas populares nas políticas culturais: uma disputa de sentidos. pragMATIZES, v. 5, n. 8, p. 68-81, 2015. https://doi.org/10.22409/pragmatizes2015.8.a10402

18. CAPELLA, Ana Cláudia N.; BRASIL, Felipe G. Análise de políticas públicas: uma revisão da literatura sobre o papel dos subsistemas, comunidades e redes. Novos Estudos, v. 101, p. 57-76, 2015. http://dx.doi.org/10.1590/S010133002015000100003

19. CARLOS, Euzeneia. Movimentos sociais e sistema político nas teorias dos movimentos sociais. Interseções, v. 17, n. 1, p. 15-53, 2015a. https://doi. org/10.12957/irei.2015.18042

20. CARLOS, Euzeneia. Movimentos sociais e instituições participativas efeitos do engajamento institucional nos padrões de ação coletiva. Revista Brasileira de Ciências Sociais, v. 30, n. 88, p. 83-99, 2015b. http://dx.doi. org/10.17666/308883-98/2015

21. CARLOS, Euzeneia; DOWBOR, Monika; ALBUQUERQUE, Maria do Carmo. Movimentos sociais e seus efeitos em políticas públicas: balanço do debate e proposições analíticas. Civitas, v. 17, n. 2, p. 360-378, 2017. http://dx.doi. org/10.15448/1984-7289.2017.2.25925

22. CARRARA, Sérgio. Políticas e direitos sexuais no Brasil contemporâneo. Bagoas, v. 4, n. 5, p. 131-147, 2010. Disponível em: https://periodicos.ufrn.br/ bagoas/article/view/2316

23. CARREIRA, Denise. Igualdade e diferenças nas políticas educacionais: a agenda das diversidades nos governos Lula e Dilma, 2015. Tese (Doutorado em Educação). Faculdade de Educação, Universidade de São Paulo, São Paulo, 2015.

24. CAYRES, Domitila C. Ativismo institucional e interações estado-movimentos sociais. BIB, n. 82, p. 81-104, 2017. Disponível em: http://anpocs.org/index.php/ edicoes-anteriores-es/bib-82/10586-ativismo-institucional-e-interacoes-estadomovimentos-sociais/file 
25. CRUZ, Rodrigo. Do protesto às urnas: as campanhas em defesa da causa homossexual nas eleições de 1982. Revista Brasileira de Ciência Política, n. 22, p. 233-284, 2017. http://dx.doi.org/10.1590/0103-335220172207

26. CÔRTES, Soraya V. Introdução: atores, mecanismos e dinâmicas participativas. In: CÔRTES, Soraya V. (Org.). Participação e saúde no Brasil. Rio de Janeiro: Editora Fiocruz, 2009. p. 19-39.

27. DANILIAUSKAS, Marcelo. Relações de gênero, diversidade sexual e políticas públicas de educação: uma análise do Programa Brasil sem Homofobia, 2011. Dissertação (Mestrado em Educação). Faculdade de Educação, Universidade de São Paulo, São Paulo, 2011.

28. DE LA DEHESA, Rafael. El sexo y la revolución: la liberación lésbico-gay y la izquierda partidaria en Brasil. Revista de Estudios Sociales, n. 28, p. 44-55, 2007. Disponível em: http://journals.openedition.org/revestudsoc/19157

29. DOWBOR, Monika; CARLOS, Euzeneia; ALBUQUERQUE, Maria do Carmo. As origens movimentalistas de políticas públicas: proposta analítica aplicada às áreas de criança e adolescente, direitos humanos e saúde. Lua Nova, n. 105, p. 47-80, 2018. http://dx.doi.org/10.1590/0102-047080/105

30. FACCHINI, Regina. Movimento homossexual no Brasil: recompondo um histórico. Cadernos AEL, v. 10, n. 18/19, p. 81-125, 2003. Disponível em: https:// www.ifch.unicamp.br/ojs/index.php/ael/article/view/2510

31. FERNANDES, Felipe B. M. A agenda anti-homofobia na educação brasileira (2003-2010), 2011. Tese (Doutorado em Ciências Humanas). Centro de Filosofia e Ciências Humanas, Universidade Federal de Santa Catarina, Florianópolis, 2011.

32. FERREIRA, Daniela D.; LOTTA, Gabriela S. Burocratas: atores entre as fronteiras do Estado e da sociedade. Trabalho apresentado no 40o Encontro Anual da Associação Nacional de Pós-Graduação em Ciências Sociais, Caxambu, MG, 2016.

33. GALVÃO, Jane; BASTOS, Francisco I.; NUNN, Amy. The Brazilian response to AIDS from the 1980s to 2010: civil society, mobilization and AIDS policy. Global Health Governance, v. 11, n. 1, p. 2-22, 2012.

34. GRANGEIRO, Alexandre; SILVA, Lindinalva L. da; TEIXEIRA, Paulo R. Resposta à Aids no Brasil: contribuições dos movimentos sociais e da reforma sanitária. Revista Panamericana de Salud Pública, v. 26, n. 1, p. 87-94, 2009. Disponível em: http://www.scielosp.org/scielo.php?script=sci_ arttext\&pid =S1020-49892009000700013

35. GURZA LAVALLE. Adrian et al. Movimentos sociais, institucionalização e domínios de agência. Texto para Discussão - CEM, n. 19, p. 1-40, 2017.

36. GURZA LAVALLE, Adrian et al. Movimentos sociais, institucionalização e domínios de agências. In: GURZA LAVALLE, Adrian et al. Movimentos sociais e institucionalização: políticas sociais, raça e gênero no Brasil pós-transição. Rio de Janeiro: Ed. UERJ, 2019. p. 21-86.

37. LACERDA, Alice P. de; MARQUES, Carolina C.; ROCHA, Sophia C. Programa Cultura Viva: uma nova política do Ministério da Cultura. In: RUBIM, Antonio 
A. C. (Org.). Políticas culturais no Governo Lula. Salvador: EDUFBA, 2010. p. 111-132.

38. LAURENTINO, Arnaldo C. N. Políticas públicas de saúde para a população LGBT: da criação do SUS à implementação da Política Nacional de Saúde Integral de LGBT, 2015. Dissertação (Mestrado em Educação Profissional em Saúde). Escola Politécnica de Saúde Joaquim Venâncio, Fundação Oswaldo Cruz, Rio de Janeiro, 2015.

39. MATTOS, Ruben A. de. A integralidade na prática (ou sobre a prática da integralidade). Cadernos de Saúde Pública, v. 20, n. 5, p. 1411-1416, 2004. http://dx.doi.org/10.1590/S0102-311X2004000500037

40. MATTOS, Ruben A. de. Os sentidos da integralidade: algumas reflexões acerca de valores que merecem ser defendidos. In: PINHEIRO, Roseni; MATTOS, Ruben A. de (Orgs.). Os sentidos da integralidade na atenção e no cuidado à saúde. Rio de Janeiro: UERJ, IMS: ABRASCO, 2009. p. 43-68.

41. MELLO, Luiz et al. Políticas de saúde para lésbicas, gays, bissexuais, travestis e transexuais no Brasil: em busca de universalidade, integralidade e equidade. Sexualidad, Salud y Sociedad, n. 9, p. 7-28, 2011. http://dx.doi.org/10.1590/ S1984-64872011000400002

42. NATALINO, Marco A. et al. Constituição e política de direitos humanos: antecedentes, trajetória e desafios. Políticas Sociais: acompanhamento e análise, v. 3, n. 17, p. 66-131, 2009. Disponível em: http://repositorio.ipea.gov.br/ handle/11058/4326

43. PAIVA, Vera. Psicologia na saúde: sociopsicológica ou psicossocial? Inovações do campo no contexto da resposta brasileira à AIDS. Temas em Psicologia, v. 21, n. 3, p. 531-549, 2013. http://dx.doi.org/10.9788/TP2013.3-EE00-PT

44. PARKER, Richard. Building the foundations for the response to HIV/AIDS in Brazil: the development of HIV/AIDS policy, 1982 - 1996. Divulgação em Saúde para Debate, v. 27, p. 143-183, 2003.

45. PENNA, Camila. A relação de parceria entre o INCRA e os movimentos sociais no processo de implementação das políticas de reforma agrária. Interseções, n. 17, v. 1, p. 165-188, 2015. https://doi.org/10.12957/irei.2015.18052

46. PEREIRA, Adriana J.; NICHIATA, Lúcia Y. I. A sociedade civil contra a Aids: demandas coletivas e políticas públicas. Ciência \& Saúde Coletiva, v. 16, n. 7, p. 3249-3257, 2011. http://dx.doi.org/10.1590/S1413-81232011000800024

47. PEREIRA, Matheus M. Da saúde pública à homofobia: spillover e as transformações nas reivindicações do movimento LGBT em interações com o Estado. Revista Psicologia Política, v. 17, n. 38, p. 141-165, 2017.

48. PEREIRA, Matheus M. Oportunidades políticas em um presidencialismo de coalizão. Lua Nova, n. 105, p. 217-252, 2018a. http://dx.dol.org/10.1590/0102217252/105

49. PEREIRA, Matheus $M$. Um confronto político no presidencialismo de coalizão: os resultados do confronto entre o movimento LGBT e o movimento cristão pró-vida e pró-família (2003-2014). 2018. 303f. Tese (Doutorado em 
Sociologia). Instituto de Filosofia e Ciências Humanas, Universidade Federal do Rio Grande do Sul, Porto Alegre, 2018b.

50. PETTINICCHIO, David. Institutional activism: reconsidering the insider/ outsider dichotomy. Sociology Compass, v. 6, n. 6, p. 499-510, 2012. Disponível em: https://ssrn.com/abstract $=2508870$

51. RAMOS, Sílvia. O Papel das ONGs na construção de políticas de saúde: a Aids, a saúde da mulher e a saúde mental. Ciência \& Saúde Coletiva, v. 9, n. 4, p. 1067-1078, 2004. http://dx.doi.org/10.1590/S1413-81232004000400027

52. RAMOS, Sílvia; CARRARA, Sérgio. A constituição da problemática da violência contra homossexuais: a articulação entre ativismo e academia na elaboração de políticas públicas. Physis: Revista de Saúde Coletiva, v. 16, n. 2, p. 185-205, 2006. http://dx.doi.org/10.1590/S0103-73312006000200004

53. RECH, Carla M. Atores estatais e não estatais na implementação de políticas públicas: o caso do Programa de Desenvolvimento Sustentável dos Territórios Rurais. IDeAS, v. 10, n. 1, p. 117-137, 2016. Disponível em: https://revistaideas. ufrrj.br/ojs/index.php/ideas/article/view/183

54. RUBIM, Antônio A. C. Políticas culturais no governo Lula. In: RUBIM, Antônio A. C. (Org.). Políticas culturais no governo Lula. Salvador: EDUFBA, 2010. p. 9-24.

55. SANTOS, Josciene et al. As políticas públicas para a diversidade cultural brasileira. In: RUBIM, Antônio A. C. (Org.). Políticas culturais no governo Lula. Salvador: EDUFBA, 2010. p. 265-286.

56. SILVA, Marcelo K. Atores, espaços e repertórios: a atuação de movimentos sociais ätravés das fronteiras da sociedade civil e do Estado. In: SCHERER-WARREN, Ilse; LÜCHMANN, Lígia H. H. (Orgs.). Movimentos sociais e engajamento político: trajetórias e tendências analíticas. Florianópolis: Editora UFSC, 2015. p. 133-160.

57. SILVA, Marcelo K.; OLIVEIRA, Gérson de L. A face oculta(da) dos movimentos sociais: trânsito institucional e intersecção Estado-Movimento - uma análise do movimento de Economia Solidária no Rio Grande do Sul. Sociologias, v. 13, n. 28, p. 86-124, 2011. http://dx.doi.org/10.1590/S1517-45222011000300005

58. SIMIELLI, Lara E. R. Coalizões em educação no Brasil: relação com o governo e influência sobre o Plano de Desenvolvimento da Educação (PDE). Revista de Administração Pública, v. 47, n. 3, p. 567-586, 2013. http://dx.doi.org/10.1590/ S0034-76122013000300002

59. SKOCPOL, Theda. Why I am an Historical Institutionalist. Polity, v. 28, n. 1, p. 103-106, 1995. http://dx.doi.org/10.2307/3235190

60. SKOCPOL, Theda. Bringing the state back in: strategies of analysis in current research. In: EVANS, Peter; RUESCHEMEYER, Dietrich; SKOCPOL, Theda (Orgs.). Bringing the state back in. Cambridge: Cambridge University Press, 1985. p. 3-37.

61. TARROW, Sidney. O poder em movimento: movimentos sociais e confronto político. Petrópolis: Vozes, 2009. 
62. TATAGIBA, Luciana. Desafios da relação entre movimentos sociais e instituições políticas: o caso do movimento de moradia da cidade de São Paulo - primeiras reflexões. Colombia Internacional, v. 71, p. 63-83, 2010. Disponível em: http://www.scielo.org.co/scielo.php?script=sci abstract\&pid =S0121-56122010000100004

63. TATAGIBA, Luciana; ABERS, Rebecca; SILVA, Marcelo K. Movimentos sociais e políticas públicas: ideias e experiências na construção de modelos alternativos. In: PIRES, Roberto; LOTTA, Gabriela; OLIVEIRA, Vanessa E. Burocracia e políticas públicas no Brasil: interseções analíticas. Brasília: Ipea/Enap, 2018. p.106-138.

64. TATAGIBA, Luciana; TEIXEIRA, Ana Claudia C. Efeitos combinados dos movimentos de moradia sobre os programas habitacionais autogestionários. Revista de Sociologia e Política, v. 24, n. 58, p. 85-102, 2016. http://dx.doi. org/10.1590/1678-987316245804

Recebido em: 16 ago. 2019. Aceito em: 12 nov. 2019. 